CZU: 634.7

https://doi.org/10.53082/1857-3142.21.86.02

\section{Influenta conditiillor climatice asupra dezvoltării unor soiuri de măceș în Republica Moldova}

Parascovia SAVA, doctor habilitat în științe agricole, https://orcid.org/0000-0001-7902-1039;

email:psava2110@rambler.ru;

\section{Elena GHERASIMOVA,}

https://orcid.org/0000-0003-4246-2521

Institutul Ştiinţifico-Practic de Horticultură şi Tehnologii Alimentare

Rezumat. în lucrare sunt prezentate rezultatele cercetărilor efectuate referitor la fazele fenologice de dezvoltare a plantelor de măces la soiurile: Vitaminnîi VNIVI, Voronțovschi în perioada anilor 2016-2018. în urma cercetărilor s-a stabilit că desfacerea mugurilor s-a produs între 01.04 și 10.04, înflorirea - între 05.05 și 15.05, maturarea fructelor - între 10.07 și 18.07. Durata medie dintre fazele de dezmugurire și înflorire a atins 36-37 de zile, iar dintre fazele de înflorire și maturare a fructelor aceasta a variat între 61 și 64 de zile. Recolta maximă de 7,5 t/ha a fost obținută în anul 2016 la soiul Vitaminnîi VNIVI, iar la soiul Vorontovschi II recolta maximă de 7,0 t/ha a fost obținută în anul 2018. Masa medie a fructului de măceș la soiurile studiate a variat între 0,9 si 1,1 g. Recolta medie a fructelor de măceș la soiurile studiate a variat între $5,7 \mathrm{t} / \mathrm{ha}$ (soiul Voronțovschi II) și 6,2 t/ha (soiul Vitaminnîi).

Cuvinte-cheie: măceș, soiuri, fenofaze, recolta de fructe, condiții climatice ale anului.

Abstract. The paper presents the results of research conducted on the phenological phases of development of rosehip plants in the varieties: Vitamins VNIVI, Voronțovschi during the years 2016-2018. As a result of research it was established that: bud opening took place between 01.04-10.04., the flowering between 05.05-15.05., fruit ripening between 10.07-18.07. The average duration between of the budding and flowering phases reached 36-37 days, and between of the flowering and the fruits ripening phases it varied between 61-64 days. The maximum harvest was obtained in 2016 on the variety Vitaminii VNIVI $(7.5 \mathrm{t} / \mathrm{h})$ and the maximum harvest was obtained in $\mathbf{2 0 1 8}$ for the variety Voronțovschi II (7.0 t/ha). The average mass of rosehip fruits on the studied varieties varied between 0.9-1.1 g. The average harvest of the studied rosehips varieties varied between $5.7 \mathrm{t} / \mathrm{ha}$ (variety Voronțovschi II) and 6.2 t/ha (variety Vitaminii VNIVI).

Keywords: rosehip, varieties, phenophases, fruit yield, climatic conditions of year.

\section{INTRODUCERE}

Măceşul (Rosa) face parte din familia Rosaceae. În popor este cunoscut sub denumirile de măceş, trandafir sălbatic, răsură, rujă, rug, scobar. Pe globul pământesc există peste 200 de specii de măceş. Marea majoritate a speciilor de măceş vegetează spontan în climatul temperat şi cald, fiind extinse până la $68^{\circ}$ latitudine nordică. Flora spontană a României cuprinde 30 de specii de măceș, dintre care 8 sunt cultivate. Cercetările întreprinse în România confirmă că unele specii de măceș (Rosa tomentosa Sm., R. Micrantha Sm., $R$. rubiginosa L., $R$. eliptica Tausch s..a.) au o valoare de 2-8 ori mai mare în vitamina $C$ decât Rosa canina, iar Rosa pendulina L. are un conținut de 10 ori mai mare (Crăciun F. ș.a., 1976).

În Republica Moldova se întâlnesc 29 de specii de măceș, dintre care 8 sunt cultivate ca plante decorative (R. Rosa Facida, R. Acicularis, R. Majalis, R. Rubrifolia, $R$. Damascena). Un aport deosebit în această direcție o aduc instituțiile științifice republicane (Grădina Botanică a Academiei de Științe a Moldovei, Întreprinderea Municipală „Grădina Dendrologică” din Chișinău, creată pe baza fostei Grădinii Botanice), gospodăria mixtă dendrofloricolă „Floribel” din Bălți, Parcul Dendrariu din Tiraspol și foarte mulți amatori (Tarhon P., 2013).

Măceşul se caracterizează prin fructe bogate în vitamina $\mathrm{C}$, fiind în medie de 50 de ori mai bogat decât lămâile şi de 100 de ori decât merele. Fructele de măceș mai conţin vitaminele $B_{2}, K$ şi $P P$, provitamina $\mathrm{A}$, zaharuri, substanţe minerale, $\mathrm{K}, \mathrm{Ca}, \mathrm{Fe}, \mathrm{Mg}$, acid malic, acid citric, uleiuri volatile, lecitină etc. Florile, fructele şi seminţele de măceş au o mare întrebuinţare în industria alimentară, pentru prepararea de siropuri, sucuri, marmelade etc., iar în medicină se folosesc în tratarea anemiei, a bolilor căilor urinare, a constipaţiei şi bronşitei acute, gripei, laringitei etc. Prin distilare, din petalele unor specii de trandafir se obțin uleiuri, parfumuri etc.

Perioada de vegetaţie la măceşii cu ghimpi este de 150-160 de zile, iar la măceşii fără ghimpi - cu o lună mai scurtă. În zonele de şes înfloresc târziu, la mijlocul lunii mai, iar în zonele colinare şi montane cu o lună mai târziu, la mijlocul lunii iunie, dar înflorirea se eșalonează pe 20-25 de zile. Măceşul fructifică pe ramuri de 1 an, crescute pe ramuri de 2 ani, producţiile cele mai mari se obţin în anul al 3-lea, pe partea mediană a tulpinilor. Măceșii cu ghimpi sunt mai iubitori de căldură, din care cauză sunt răspândiți în zonele cu altitudine mai mică, precum și în regiunile sudice. Datorită sistemului radicular puternic sunt foarte rezistenți la temperaturi scăzute și înghețuri. Speciile de Rosa sunt foarte rezistente la temperaturi scăzute, în perioada de repaus suportând minime de la -25 până la $-30{ }^{\circ} \mathrm{C}$, iar primăvara scapă ușor de înghețuri datorită înfloririi târzii (Burmistrov, 1985, p. 252-256; Statescu C., 1989, 352 p.).

Temperaturile ridicate inhibă formarea și păstrarea 
unei cantități ridicate de acid ascorbic în măceși, în timp ce temperaturile moderate favorizează aceste procese. Precipitațiile abundente influențează pozitiv acumulările de acid ascorbic, deoarece intensitatea proceselor de acumulare este strâns legată de cantitatea de apă din măceși (Mladin G., Mladin P., 1992, 235 p.).

\section{MATERIALE ȘI METODE DE CERCETARE}

Cercetările referitor la desfășurarea fazelor fenologice de dezvoltare a plantelor de măceș în funcţie de soi şi de condiţiile climatice ale anului în zona de centru a Republicii Moldova au fost efectuate pe sectorul experimental al Stațiunii Tehnologico-Experimentale „Codru” al IP ŞPHTA, unde în baza metodelor stabilite pentru arbuștii fructiferi s-au determinat perioadele de dezvoltare a plantelor: desfacerea mugurilor, înflorirea, fructificarea și aprecierea calitativă a recoltei pe parcursul anilor 2016-2018. Ca obiecte de studiu au servit 2 soiuri de măceş: Vitaminnîi VNIVI, Voronțovschi.

\section{REZULTATE ȘI DISCUȚII}

Dezvoltarea plantelor, precum şi perioada, durata desfăşurării fazelor fenologice sunt influenţate de mai mulţi factori, inclusiv de condiţiile climatice ale anului, ce include acumularea sumei de temperaturi necesare pentru parcurgerea de către soiul cultivat a fiecărei faze în parte, tehnologia de întreţinere a plantelor etc.

Cercetările efectuate ne-au permis să determinăm la soiurile studiate perioadele desfășurării fazelor fe- nologice de dezvoltare a plantelor de măceș şi recolta obţinută, rezultatele fiind prezentate în tabelul 1.

În urma cercetărilor efectuate, conform datelor incluse în tabelul 1, s-a determinat perioada de desfacere a mugurilor la soiurile de măceş studiate, care s-a desfăşurat între 01.04 și 05.04, perioada de înflorire între 15.05 și 20.06, care durează 35 de zile. Maturarea fructelor de măceş începe de la 10.07 şi se termină la 01.09. Durata medie dintre fazele de dezmugurire şi înflorire a plantelor de măceş la soiurile studiate constituie 36-37 de zile, iar dintre fazele de înflorire şi maturare a fructelor aceasta variază între 61 și 64 de zile. În figura 1 sunt prezentate florile de măceș, iar soiurile studiate sunt prezentate în figura 2: a) soiul Vitaminnîi VNIVI; b) soiul Vorontovschi II.

Cea mai timpurie desfacere a mugurilor la ambele soiuri de măceş a fost înregistrată în anul 2016 (01.04), iar cea mai târzie în anul 2017 (10.04). Faza fenologică de înflorire la soiurile de măceş studiate s-a desfăşurat cel mai timpuriu în anul 2018 (05.05), iar cea mai târzie în anul 2016 (15.05). Cea mai timpurie maturare a fructelor la soiul Vitaminnîi VNIVI a fost în anul 2018 (10.07) şi cea mai târzie în anul 2017 (18.07), iar la soiul Voronțovschi II cea mai timpurie maturare a fructelor s-a înregistrat în anul 2017 (13.07).

Producţia medie de fructe la o tufă a variat între 3,4 și 3,7 kg, iar producţia medie de fructe de măceș la o unitate de suprafaţă a constituit 5,7 și 6,2 t/ha. Cel mai favorabil an pentru soiul Vitaminnîi VNIVI a fost 2016, când s-a obţinut cea mai înaltă recoltă, atât la tufă $(4,5 \mathrm{~kg})$, cât şi la hectar $(7,5 \mathrm{t})$, iar cea mai mică s-a obţinut în anul 2018 - 3,2 kg/tufă şi, respectiv, 5,3 t/ha.

Pentru soiul Voronțovschi II cel mai favorabil an

Perioada de desfășurare a fazelor fenologice de dezvoltare a soiurilor de măceș

\begin{tabular}{|c|c|c|c|c|c|c|c|c|}
\hline $\begin{array}{c}\text { Denumirea soi- } \\
\text { ului }\end{array}$ & $\begin{array}{l}\text { Desfa- } \\
\text { cerea } \\
\text { muguri- } \\
\text { lor, data }\end{array}$ & $\begin{array}{l}\text { Durata } \\
\text { dintre } \\
\text { faze, } \\
\text { zile }\end{array}$ & $\begin{array}{c}\text { Durata } \\
\text { înfloririi, } \\
\text { perioada }\end{array}$ & $\begin{array}{c}\text { Durata } \\
\text { dintre } \\
\text { faze, } \\
\text { zile }\end{array}$ & $\begin{array}{l}\text { Maturarea } \\
\text { fructelor, } \\
\text { perioada }\end{array}$ & $\begin{array}{c}\text { Masa } \\
\text { unui } \\
\text { fruct, g }\end{array}$ & $\begin{array}{c}\text { Producția } \\
\text { la o tufă, } \\
\text { kg }\end{array}$ & $\begin{array}{c}\text { Re- } \\
\text { colta la } \\
\text { hectar, } t / \\
\text { ha }\end{array}$ \\
\hline \multicolumn{9}{|c|}{ Vitaminnîi VNIVI } \\
\hline 2016 & 01.04 & 44 & $\begin{array}{l}15.05- \\
20.06 \\
\end{array}$ & 51 & $15.07-01.09$ & 1,0 & 4,5 & 7,5 \\
\hline 2017 & 10.04 & 33 & $\begin{array}{l}13.05- \\
30.05\end{array}$ & 66 & $18.07-05.09$ & 1,0 & 3,5 & 5,8 \\
\hline 2018 & 02.04 & 34 & $\begin{array}{l}06.05- \\
25.05\end{array}$ & 65 & $10.07-01.09$ & 0,8 & 3,2 & 5,3 \\
\hline Media & & 37 & & 61 & & 0,9 & 3,7 & 6,2 \\
\hline \multicolumn{9}{|c|}{ Voronțovschi II } \\
\hline 2016 & 01.04 & 44 & $\begin{array}{l}15.05- \\
20.06\end{array}$ & 61 & $15.07-01.09$ & 1,2 & 3,6 & 6,0 \\
\hline 2017 & 10.04 & 35 & $\begin{array}{l}15.05- \\
25.05\end{array}$ & 59 & $13.07-30.08$ & 1,0 & 2,5 & 4,3 \\
\hline 2018 & 04.04 & 29 & $\begin{array}{l}05.05- \\
25.05 \\
\end{array}$ & 71 & $15.07-01.09$ & 1,2 & 4,2 & 7,0 \\
\hline Media & & 36 & & 64 & & 1,1 & 3,4 & 5,7 \\
\hline
\end{tabular}




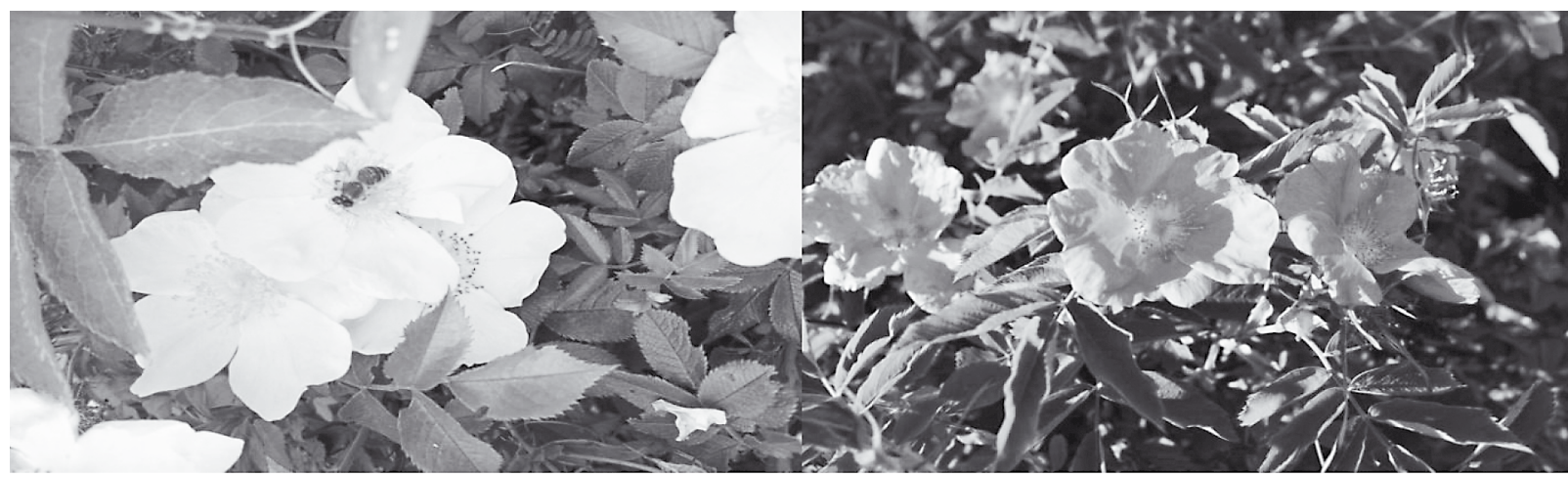

Figura 1. Flori de măceș

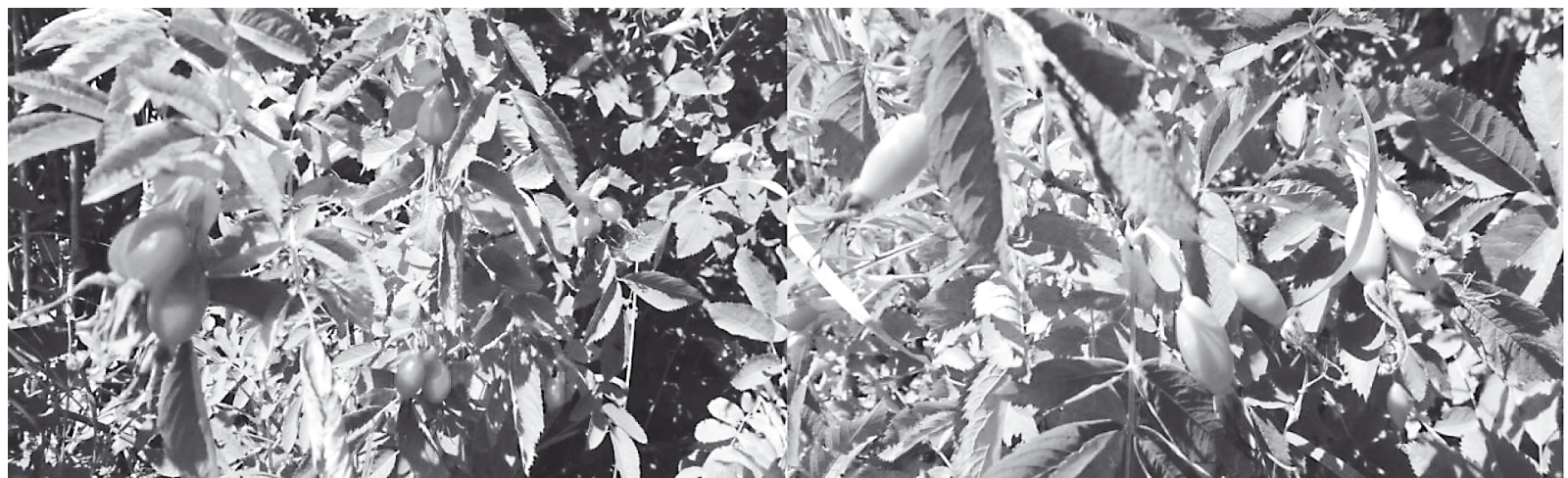

a

b

Figura 2: a) soiul Vitaminnîi VNIVl; b) soiul Voronțovschi II

a fost 2018, când s-a obţinut cea mai înaltă recoltă, atât la tufă $(4,2 \mathrm{~kg})$, cât şi la hectar $(7,0$ t), iar cea mai mică s-a obţinut în anul 2017 - 2,5 kg/tufă şi, respectiv, 4,3 t/ha. Masa fructelor de măceş la soiul Vitaminnîi VNIVI a variat între 0,8 și 1,0 g, iar la soiul Voronțovschi II - între 1,0 și 1,2 g. Recoltarea fructelor de măceş este eşalonată, se începe în luna august și durează până la primele înghețuri de toamnă.

\section{CONCLUZII}

Cercetările efectuate referitor la adaptabilitatea soiurilor de măceș studiate, fazele fenologice de dezvoltare a plantelor şi producţia obţinută în condiţiile de cultivare ale zonei de centru a Republicii Moldova ne-au permis să stabilim că:

- desfacerea mugurilor s-a desfășurat între 01.04 (anul 2016) și 10.04 (anul 2017); înflorirea - între 05.05 (anul 2018) și 15.05 (anul 2016); maturarea fructelor între 10.07 (anul 2018) și 18.07 (anul 2017);

- durata medie dintre fazele de dezmugurire şi înflorire a constituit 36-37 de zile, iar dintre fazele de înflorire şi maturare a fructelor variază între 61 și 64 de zile;

- cel mai favorabil an pentru soiul Vitaminnîi VNIVI a fost 2016 , cu o recoltă de 7,5 t/ha, iar pentru soiul Voronțovschi II a fost anul 2018, cu o recoltă de 7,0 t/ha;

- masa medie a fructelor de măceş la soiurile studiate a variat între 0,9 și $1,1 \mathrm{~g}$ :
- recolta medie a fructelor de măceş la soiurile studiate a variat între 5,7 t/ha (soiul Voronțovschi II) şi 6,2 t/ha (soiul Vitaminnîi).

Notă: Cercetările au fost efectuate în cadrul proiectului „Program de Stat” 20.80009.5107.22A „Elaborarea şi modernizarea tehnologiilor durabile şi ecologice ale speciilor pomicole şi bacifere în condiţiile schimbărilor climatice”.

\section{BIBLIOGRAFIE} promizdat, 1985, p. 252-256.

2. Crăciun F., Bujor O., Alexam M. Farmacia naturii. București, Editura Ceres, 1976, 366 p.

3. M̉ladin G., Mladin P. Cultura arbuștilor fructiferi pe spații restrânse. București, Editura Ceres, 1992, 252 p.

4. Sorta şipovnika http;//ergashaka.ru.-novye-sorta shipovnika, 2014, p.1-3.

5. Statescu C. Botanica medicală veterinară. București, Editura Ceres, 1989, 352 p.

6. Tarhon P. Măceșul Rosa canina L., Arbori și arbuști fructiferi. Chișinău, 2019, 108 p.

RECENZIE ŞTIINȚIFICĂ - Ilie DONICA, doctor habilitat în ştînţe agricole, profesor cercetător.

Materialul a fost prezentat la 31.05.2021. 